\title{
Influence of Calcium on the Inotropic Actions of Hyperosmotic Agents, Norepinephrine, Paired Electrical Stimulation, and Treppe
}

\author{
James T. Willerson, J. Stanley Crie, Robert C. Adcock, \\ Gordon H. Templeton, and Kern Wildenthal \\ From the Pauline and Adolph Weinberger Laboratory for Cardiopulmonary \\ Research, Departments of Internal Medicine and Physiology, The University of \\ Texas Southwestern Medical School, Dallas, Texas 75235
}

\begin{abstract}
A в S T R A C T To analyze the interaction of calcium ion concentration with hypertonic agents and with other inotropic interventions, isolated right ventricular cat papillary muscles were studied under isometric conditions in Krebs-Ringer bicarbonate solution. Extracellular calcium concentrations were varied between 2.5 and $11.0 \mathrm{mM}$. Maximal inotropic effects occurred between 5 and $8.0 \mathrm{mM}$ calcium and further elevation to $11.0 \mathrm{mM}$ was without additional influence. The effect of hyperosmotic sucrose and mannitol on papillary muscle performance was compared with that of $10^{-6} \mathrm{M}$ norepinephrine at calcium concentrations of 2.5 and $10.0 \mathrm{mM}$ and with paired electrical stimulation in $10.0 \mathrm{mM}$ calcium. Both norepinephrine and the hyperosmotic agents produced significant increases in developed tension and in the maximal rate of tension rise $(\mathrm{d} T / \mathrm{d} t)$ in Krebs-Ringer in 2.5 and $4.0 \mathrm{mM}$ calcium. In $10 \mathrm{mM}$ calcium norepinephrine increased developed tension and $\mathrm{d} T / \mathrm{d} t$, but sucrose and mannitol caused no change or small reductions in both. Paired electrical stimulation, like hyperosmolality, caused no increase in $\mathrm{d} T / \mathrm{d} t$ in $10 \mathrm{mM}$ calcium.
\end{abstract}

The presence of a potent pharmacological inhibitor of systolic calcium transfer across the cell membrane $\left(\mathrm{D} 600,10^{-6} \mathrm{M}\right)$ reduced developed tension and $\mathrm{d} T / \mathrm{d} t$ by $76 \pm 2.7$ and $74 \pm 2.0 \%$, respectively, and prevented and in fact reversed the expected increase in $\mathrm{d} T / \mathrm{d} t$ associated with an increase in rate of stimulation (treppe). However, hypertonic mannitol and paired

Dr. Wildenthal holds a U. S. Public Health Service Career Development Award (HL 70125) and Dr. Willerson is an Established Investigator of The American Heart Association.

Received for publication 29 May 1973 and in revised form 4 June 1974. pacing persisted in causing marked increases in developed tension and $\mathrm{d} T / \mathrm{d} t$ even in the presence of D600, suggesting that their inotropic effects are not dependent on increased intracellular transfer of calcium during systole through cell membrane channels in which D600 acts as a competitive inhibitor.

The results of these studies suggest that apparent functional saturation of intracellular calcium receptor sites eliminates any additional inotropic effect of hyperosmolality or paired pacing. The data are compatible with the hypothesis that the inotropic effects of hyperosmolality and of paired pacing result from an increase in calcium concentration at the myofilaments during contraction. The increase induced by hyperosmolality might occur because of an increase in the total amount of calcium released into the cytosol with each action potential and/or as a passive consequence of cellular dehydration. Norepinephrine has the capacity to increase contractility even when intracellular calcium receptor sites appear to be functionally saturated, suggesting that it may act at least in part by a mechanism that is independent of changes in net intracellular calcium concentration.

\section{INTRODUCTION}

The net inotropic effect of many interventions can vary widely depending on the extracellular concentration of calcium (1-5). Undoubtedly, part of the reason for this is simply that the positive inotropic influence of high calcium, per se, causes improvement in muscle function to near-maximal levels, so that subsequent inotropic interventions can add little more to the muscle's performance. In addition, if a given agent acts by changing intracellular calcium concentration by one 

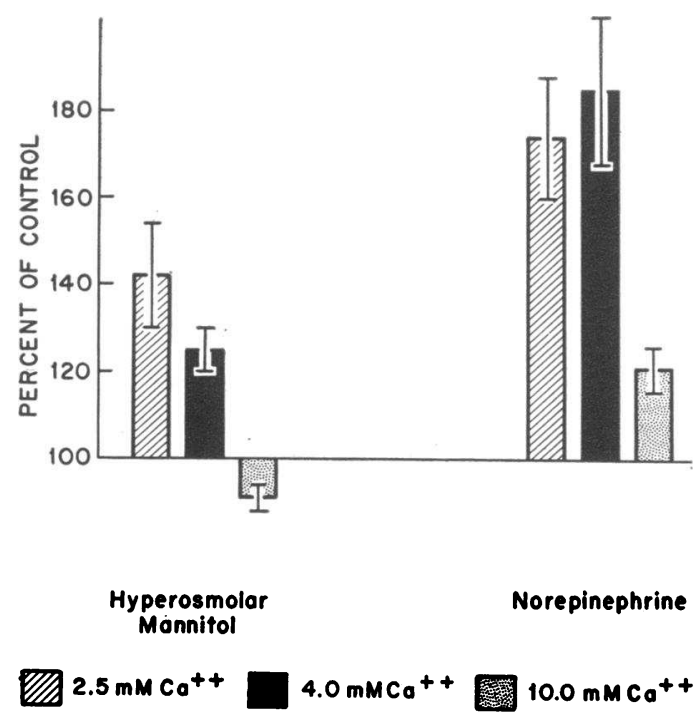

FIGURE 1 The influence of mannitol and norepinephrine on developed tension at extracellular calcium concentrations of $2.5,4.0$, and $10.0 \mathrm{mM}$ is shown. The figure demonstrates that mannitol loses its inotropic effect in $10.0 \mathrm{mM}$ calcium whereas that of norepinephrine is reduced but persists.

means or another, it might be supposed that prior elevation of extracellular calcium concentration above a critical level could preempt any changes the agent might otherwise produce.

Recent studies have demonstrated that hyperosmotic mannitol and sucrose have an inotropic effect in intact animals $(6,7)$ and in isolated heart muscle $(8,9)$. Hyperosmotic agents have also been shown to improve ventricular function, reduce the extent of myocardial injury, and improve total and collateral coronary blood flow during acute coronary insufficiency in anesthetized animals (10) and to reduce hypoxic depression in isolated cat papillary muscle (11). When osmolality rises to over 100 mosmol above control levels ( $>400$ mos$\mathrm{mol} / \mathrm{kg} \mathrm{H}_{2} \mathrm{O}$ ), both the contractile elements and the viscoelastic components of the myocardium are altered, but below that level hyperosmolality affects only the contractile elements of the heart $(9,12)$. The mechanism by which hyperosmotic agents exert their inotropic effect on contractile elements is not yet known, but Koch-Weser (8) has suggested that they may act by causing an increase in the concentration of intracellular calcium available at the myofilaments, perhaps as a passive consequence of cellular dehydration. Little and Sleator (13) have shown that hyperosmotic solutions increase the intracellular transfer of calcium from extracellular sources; however, their calculations indicated that the observed changes in calcium transfer were probably of insufficient magnitude to explain the entire inotropic effect of hyperosmolality. No other data have been available to support the contention that calcium concentration per se is linked to the inotropic effect of hyperosmotic agents.

Accordingly, the present experiments were designed to explore the interactions of the inotropic effects of hyperosmolality and increased calcium concentration. Particular attention was directed at determining whether or not prior elevation of extracellular calcium above a critical level abolishes the inotropic effect of hyperosmolality. For comparison, the interactions of calcium and paired electrical stimulation and of calcium and norepinephrine were analyzed similarly. In addition, studies were made of the ability of pharmacological blockade of systolic calcium flux to abolish the inotropic actions of hyperosmolality, paired electrical stimulation, and treppe.

\section{METHODS}

Isolated right ventricular papillary muscles were obtained from cats that had been anesthetized with intraperitoneal sodium pentobarbital $(60 \mathrm{mg} / \mathrm{kg})$. After midline thoracotomy, the heart was excised and a papillary muscle was removed from the right ventricle and transferred to a muscle bath. The bath contained Krebs-Ringer bicarbonate solution with $18 \mathrm{mM}$ glucose and calcium of $2.5-10.0 \mathrm{mM}$. The medium was equilibrated with $95 \% \mathrm{O}_{2}$ plus $5 \% \quad \mathrm{CO}_{2}$, and the temperature was held constant by an external water bath. The muscles, which contracted isometrically, were held between spring-loaded clips one of which formed the end of a rigid pin that penetrated the bottom of the bath and attached directly to a Statham G1-4-250 force transducer (Statham Instruments, Inc., Oxnard, Calif.). The end of the muscle with chordae attached was connected to a lever mounted on a rigid Palmer stand. The muscles were stimulated with impulses (20\% above threshold) through platinum electrodes placed parallel to the long axis of the muscles. Tension and its first derivative $(\mathrm{d} T / \mathrm{d} t)$

TABLE I

Effect of Increasing Extracellular Calcium Concentration on Papillary Muscle Performance

\begin{tabular}{ccccc}
\hline $\begin{array}{c}\text { Number } \\
\text { of } \\
\text { muscles }\end{array}$ & $\begin{array}{c}\text { Extra- } \\
\text { cellular } \\
\text { calcium } \\
\text { concen- } \\
\text { tration }\end{array}$ & $\begin{array}{c}\text { Resting } \\
\text { tension } \\
\pm 1 \text { SEM }\end{array}$ & $\begin{array}{c}\text { Developed } \\
\text { tension } \\
\pm 1 \text { SEM }\end{array}$ & $\begin{array}{c}\text { Maximal } \\
\text { rate of } \\
\text { tension rise } \\
\pm 1 \text { SEM }\end{array}$ \\
\hline & $m M$ & $g / m^{2}$ & $g / m^{2}$ & $g / m^{2} / \mathrm{s}$ \\
8 & 2.5 & $0.4 \pm 0.08$ & $4.5 \pm 0.65$ & $24 \pm 3.2$ \\
8 & 5.0 & $0.3 \pm 0.05 \S$ & $6.5 \pm 0.83^{*}$ & $40 \pm 5.8^{*}$ \\
8 & 8.0 & $0.2 \pm 0.04 \ddagger$ & $6.9 \pm 0.95 \ddagger$ & $45 \pm 7.6 \S$ \\
8 & 11.0 & $0.2 \pm 0.02 \S$ & $6.8 \pm 0.96 \S$ & $45 \pm 7.3 \S$ \\
\hline
\end{tabular}

The statistical comparisons are made between the calcium value for which the $P$ value is provided and the calcium value immediately preceding it.

$* P<0.001$

$\ddagger P<0.05$.

$\S P>0.05$. 
were recorded on a Hewlett-Packard direct writer (Hewlett-Packard Co., Palo Alto, Calif.). Values were subsequently corrected for cross-sectional area. The mean crosssectional area for the papillary muscles studied was 0.95 \pm 0.07 (SEM) $\mathrm{mm}^{2}$.

Eight papillary muscles, contracting at $12 / \mathrm{min}$ at an initial resting tension of $1 \mathrm{~g}$, were allowed to stabilize for $30-60 \mathrm{~min}$ at $29^{\circ} \mathrm{C}$ in Krebs-Ringer bicarbonate solution containing $2.5 \mathrm{mM}$ calcium. After initial stabilization the pacing rate and temperature were increased (to $20 / \mathrm{min}$ and $37^{\circ} \mathrm{C}$, respectively) to facilitate intracellular calcium transfer (14). After a 30-min period of stabilization the length of the muscle at which maximal tension development was present (Lmax) was determined. Control tensions and their maximum derivatives $(\max \mathrm{d} T / \mathrm{d} t)$ were then recorded, the muscle bath was rapidly emptied of its fluid content and replaced with an identical medium containing $5 \mathrm{mM}$ calcium rather than the initial $2.5 \mathrm{mM}$. Another 30 min stabilization period followed, and tensions and $\max$ $\mathrm{d} T / \mathrm{d} t$ were again recorded. Subsequently solutions containing 7.5 and $10.0 \mathrm{mM}$ calcium were evaluated in an identical manner.

Another group of eight muscles was studied in $2.5 \mathrm{mM}$ calcium at $\mathrm{L} \max$ and $37^{\circ} \mathrm{C}$ and a rate of $20 / \mathrm{min}$ after stabilization periods as described above. After control tensions and $\max \mathrm{d} T / \mathrm{d} t$ were recorded, the fluid in the bath was rapidly replaced with a new Krebs-Ringer bicarbonate solution supplemented with either mannitol (50 mosmol above control) or sucrose ( 90 mosmol above control). Another 30 -min stabilization period was provided, and tensions and $\max \mathrm{d} T / \mathrm{d} t$ were again recorded. The muscles were again immersed in the control solution for $30 \mathrm{~min}$ and repeat control contractions were recorded. Finally norepinephrine- $\mathrm{HCl}\left(10^{-6} \mathrm{M}\right)$ was added to the bath and tension was recorded after 3-4 min.

22 additional papillary muscles were tested in an identical manner except that after initial stabilization at $2.5 \mathrm{mM}$ calcium, the bathing medium was switched to one containing either 4.0 or $10.0 \mathrm{mM}$ calcium and the rest of the experiment was performed at that level.

Eight papillary muscles were evaluated in $10.0 \mathrm{mM}$ calcium under conditions identical to those previously described. After final stabilization and recording of control values, paired pacing was instituted. The absolute refractory period was determined by gradually increasing the delay between the first and second pacing stimulus by 10 -ms intervals until the first double peak contour was obtained in the developed tension tracing. Sustained paired pacing was then continued for a 2-3-min period while tensions and $\max$ $\mathrm{d} T / \mathrm{d} t$ were recorded. Peak developed tension was obtained from the maximal contraction after the initiation of paired pacing. This was nearly always the first or one of the first contractions after the onset of effective paired pacing. Only those contractions that were free of after contractions were used (15).

A final group of nine muscles was treated with D600, a potent pharmacological inhibitor of systolic calcium transfer at the cell membrane (5). The muscles were allowed to stabilize in control solution at $30^{\circ} \mathrm{C}$ and 12 contractions/ min, after which $10^{-6} \mathrm{M}$ of $\mathrm{D} 600$ was added to the bath. After 1-2 h, when contractile depression had stabilized, paired pacing was instituted as described earlier. The paired pacing was discontinued after a 2-3-min period and the muscle allowed to restabilize. Hyperosmotic mannitol was then added and tensions and $\mathrm{d} T / \mathrm{d} t$ recorded when stable. In four muscles the effect of increasing the stimulation rate
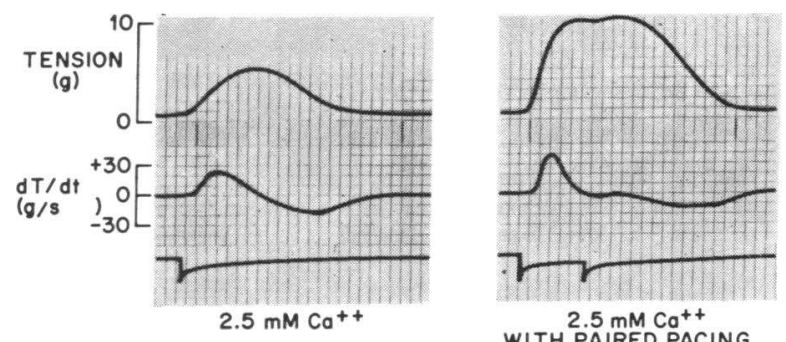

$2.5 \mathrm{mM} \mathrm{Ca}^{++}$
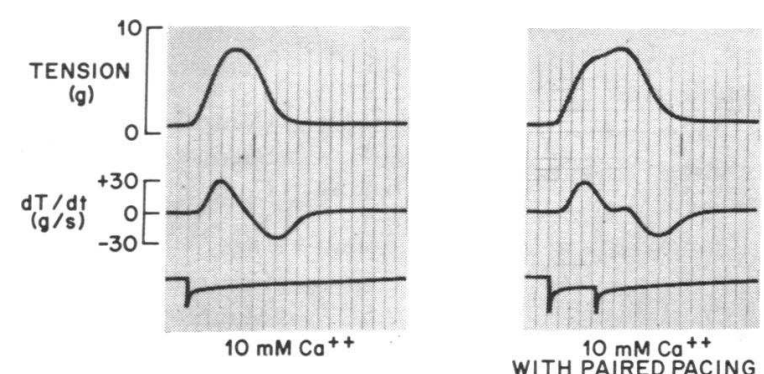

$500 \mathrm{~ms}$

FIgURE 2 The top panel demonstrates the characteristic effect of paired pacing in increasing developed tension and $\mathrm{d} T / \mathrm{d} t$ in $2.5 \mathrm{mM}$ calcium at $37^{\circ} \mathrm{C}$. The bottom panel demonstrates the absence of a significant positive inotropic effect of paired pacing when the calcium concentration is $10 \mathrm{mM}$.

(treppe effect) after the addition of D600 was also determined.

Statistical comparisons were made using Student's $t$ test for paired observations. Differences were considered significant when $P$ was less than 0.05 .

\section{RESULTS}

Calcium dose-response curve. Eight papillary muscles were studied to obtain a dose-response curve to increasing concentrations of extracellular calcium at the pacing rate of $20 / \mathrm{min}$ and temperature of $37^{\circ} \mathrm{C}$. There were significant increases in both developed tension and $\max \mathrm{d} T / \mathrm{d} t$ as the extracellular calcium concentration was increased from 2.5 to $8.0 \mathrm{mM}$ (Table I). Developed tension increased 48 and $57 \%$ in 5.0 and $7.5 \mathrm{mM}$ calcium, while maximal $\mathrm{d} T / \mathrm{d} t$ increased 67 and $88 \%$. There was no further significant increase in either developed tension or $\max \mathrm{d} T / \mathrm{d} t$ as the extracellular calcium concentration was further increased from 8.0 to $11.0 \mathrm{mM}$.

There was a significant fall in resting tensions as extracellular calcium concentration increased from 2.5 to 8.0 and $11.0 \mathrm{mM}$, possibly as the result of stress relaxation (16) or possibly simply because of a slight instability of the preparation with the passage of time.

Hyperosmotic mannitol and sucrose. Hyperosmotic mannitol (50 mosmol above control) caused increases in total developed tension of $38 \%$ in the solution con- 
TABLE II

Effect of Hypertonic Sucrose and Mannitol and $10^{-6} \mathrm{M}$ Norepinephrine on Papillary Muscle Performance at Varying Calcium Concentrations

\begin{tabular}{ccllcc}
\hline $\begin{array}{c}\text { Number } \\
\text { of } \\
\text { muscles }\end{array}$ & {$\left[\mathrm{Ca}^{++}\right]$} & \multicolumn{1}{c}{ Intervention } & $\begin{array}{c}\text { Resting } \\
\text { tension } \\
\pm 1 \mathrm{SEM}\end{array}$ & $\begin{array}{c}\text { Developed } \\
\text { tension } \\
\pm 1 \mathrm{SEM}\end{array}$ & $\begin{array}{c}\text { Maximal rate } \\
\text { of tension } \\
\text { rise } \pm 1 \mathrm{SEM}\end{array}$ \\
\hline & & & $\mathrm{g} / \mathrm{mm}^{2}$ & $\mathrm{~g} / \mathrm{mm}^{2}$ & $\mathrm{~g} / \mathrm{mm}^{2} / \mathrm{s}$ \\
4 & 2.5 & Control & $1.0 \pm 0.41$ & $5.9 \pm 0.93$ & $40 \pm 5.8$ \\
4 & 2.5 & Sucrose & $0.7 \pm 0.32^{*}$ & $8.3 \pm 0.99^{*}$ & $63 \pm 5.3^{*}$ \\
4 & 2.5 & Control 2 & $0.9 \pm 0.52$ & $4.9 \pm 0.69$ & $33 \pm 4.4$ \\
4 & 2.5 & Norepinephrine & $0.8 \pm 0.46$ & $8.6 \pm 0.89 \ddagger$ & $74 \pm 3.7^{*}$ \\
6 & 10.0 & Control & $1.1 \pm 0.19$ & $6.9 \pm 1.01$ & $59 \pm 10.6$ \\
6 & 10.0 & Sucrose & $0.9 \pm 0.16$ & $6.4 \pm 0.91$ & $54 \pm 9.4$ \\
6 & 10.0 & Control 2 & $0.6 \pm 0.12$ & $6.2 \pm 1.04$ & $52 \pm 10.0$ \\
6 & 10.0 & Norepinephrine & $0.6 \pm 0.14$ & $7.3 \pm 1.01^{*}$ & $62 \pm 9.2 \ddagger$ \\
5 & 2.5 & Control & $1.2 \pm 0.23$ & $3.7 \pm 1.16$ & $24 \pm 2.5$ \\
5 & 2.5 & Mannitol & $0.8 \pm 0.16^{*}$ & $5.1 \pm 1.40 \ddagger$ & $39 \pm 11.6 \S$ \\
5 & 2.5 & Control 2 & $0.7 \pm 0.20$ & $3.2 \pm 0.86$ & $20 \pm 5.6$ \\
5 & 2.5 & Norepinephrine & $0.7 \pm 0.20$ & $5.3 \pm 1.10^{*}$ & $49 \pm 8.8^{*}$ \\
8 & 10.0 & Control & $1.6 \pm 0.30$ & $9.7 \pm 0.76$ & $82 \pm 8.1$ \\
8 & 10.0 & Mannitol & $1.3 \pm 0.26 \S$ & $9.0 \pm 0.73 \ddagger$ & $75 \pm 8.4 \S$ \\
$6 \|$ & 10.0 & Control 2 & $1.1 \pm 0.27$ & $9.0 \pm 0.79$ & $74 \pm 9.8$ \\
$6 \|$ & 10.0 & Norepinephrine & $1.2 \pm 0.34$ & $10.9 \pm 0.99 \ddagger$ & $93 \pm 12.2^{*}$ \\
\hline
\end{tabular}

Statistical comparisons are made between each value and the control immediately preceding it.

${ }^{*} P<0.001$.

$\ddagger P<0.01$

$\S P<0.05$.

II Two of the papillary muscles developed arrhythmias when norepinephrine was added.

taining $2.5 \mathrm{mM}$ calcium and of $26 \%$ in $4.0 \mathrm{mM}$ calcium. At $10 \mathrm{mM}$ calcium a similar concentration of mannitol caused no change or a small decrease in total tension (mean - 8\%) (Fig. 1; Table II). The maximal rate of tension rise changed similarly (Table II).

As with mannitol, developed tension and $\mathrm{d} T / \mathrm{d} t$ rose significantly when hyperosmotic sucrose $(90$ mosmol above control) was added to a solution containing 2.5 $\mathrm{mM}$ calcium but remained constant or fell in the presence of $10.0 \mathrm{mM}$ calcium (Table II). With both hyperosmotic agents, resting tension tended to remain constant or to fall slightly, indicating that neither contracture nor a decrease in compliance had occurred in the muscles. The decreases in resting tension were especially marked after $30 \mathrm{~min}$ exposure to the hyperosmotic agents in $2.5 \mathrm{mM}$ calcium, suggesting that the chronic inotropic change that had occurred had induced some stress relaxation.

Norepinephrine. The addition of $10^{-6} \mathrm{M}$ norepinephrine significantly increased developed tension and $\max \mathrm{d} T / \mathrm{d} t$ in $2.5,4.0$, and $10.0 \mathrm{mM}$ calcium environments (Fig. 1; Table II). Increases in developed tension and $\max \mathrm{d} T / \mathrm{d} t$ were less in high calcium, but consistent increases persisted even at the highest concentration. Thus, developed tension rose by $21 \%$ and $\max \mathrm{d} T / \mathrm{d} t$ by $26 \%$ after the addition of $10^{-6} \mathrm{M}$ norepinephrine to a solution containing $10.0 \mathrm{mM}$ calcium. There was no significant change in resting tension.

Paired pacing in the presence of $10.0 \mathrm{mM}$ calcium. To determine whether $10.0 \mathrm{mM}$ extracellular calcium concentrations provided maximal functional intracellular calcium concentrations, eight additional papillary muscles were studied (Fig. 2; Table III). Maximal $\mathrm{d} T / \mathrm{d} t$ was not significantly changed by the use of paired pacing in the presence of $10.0 \mathrm{mM}$ calcium at $37^{\circ} \mathrm{C}$ and a pacing rate of $20 / \mathrm{min}$. Developed tension increased slightly in five of eight muscles studied. The time to peak tension also increased in these same five muscles. As noted earlier, the maximal effect of paired pacing was usually noted during the first few beats. Thereafter, sustained paired pacing produced a progressive decrease in developed tension and max $\mathrm{d} T / \mathrm{d} t$ often coinciding with the appearance of after contractions.

Influence of D600 on inotropic effect of hyperosmotic mannitol, paired pacing, and the treppe effect. 0600 
reduced developed tension and $\mathrm{d} T / \mathrm{d} t$ by $76 \pm 2.7 \%(P$ $<0.001$ ) and $74 \pm 2.0 \%(P<0.001)$, respectively (Fig. 3 ). Paired pacing and hyperosmotic mannitol produced significant increases in developed tension and $\mathrm{d} T / \mathrm{d} t$ even in the presence of D600 (Fig. 3). In contrast the positive treppe effect which is characterized by an increase in $\mathrm{d} T / \mathrm{d} t$ with increasing rate of stimulation was prevented and in fact reversed by D600 (Fig. 4). The influence of D600 on increases in developed tension as a consequence of treppe was directionally similar but not as dramatic.

\section{DISCUSSION}

Intracellular calcium levels rise in direct relation to increases in extracellular calcium, as a consequence of increased binding to sarcoplasmic reticulum, sarcolemma, mitochondria, and other cellular storage sites $(17,18)$. Correspondingly, an increased amount of calcium is released into the cytoplasm during excitation, resulting in greater binding of calcium to troponin, increased formation of actin and myosin cross bridges, and increased contractile strength (19). The maximal

TABLE III

Effect of $10 \mathrm{mM}$ Calcium and $10 \mathrm{mM}$ Calcium Combined with Paired Pacing on Papillary Muscle Performance

\begin{tabular}{|c|c|c|c|c|}
\hline & $\begin{array}{l}\text { Resting } \\
\text { tension }\end{array}$ & $\begin{array}{l}\text { Developed } \\
\text { tension }\end{array}$ & $\begin{array}{l}\text { Maximal } \\
\text { rate of } \\
\text { tension rise }\end{array}$ & $\begin{array}{l}\text { Time to } \\
\text { peak } \\
\text { tension }\end{array}$ \\
\hline & $\mathrm{g} / \mathrm{mm^{2 }}$ & $\mathrm{g} / \mathrm{m} m^{2}$ & $\mathrm{~g} / \mathrm{mm}^{2} / \mathrm{s}$ & $m s$ \\
\hline \multicolumn{5}{|c|}{$10 \mathrm{mM}$ calcium } \\
\hline 1 & 0.2 & 5.3 & 46 & 220 \\
\hline 2 & 0.5 & 8.5 & 90 & 190 \\
\hline 3 & 0.8 & 7.2 & 70 & 220 \\
\hline 4 & 0.4 & 5.1 & 33 & 300 \\
\hline 5 & 0.5 & 3.7 & 35 & 210 \\
\hline 6 & 0.7 & 3.5 & 35 & 240 \\
\hline 7 & 0.4 & 4.9 & 41 & 200 \\
\hline 8 & 0.4 & 3.9 & 39 & 180 \\
\hline Mean & 0.5 & 5.3 & 49 & 220 \\
\hline $\mathrm{SE}$ & 0.07 & 0.62 & 7.3 & 13.2 \\
\hline \multicolumn{5}{|c|}{ Paired pacing and $10 \mathrm{mM}$ calcium } \\
\hline 1 & 0.2 & 6.2 & 46 & 270 \\
\hline 2 & 0.5 & 8.5 & 90 & 200 \\
\hline 3 & 0.8 & 7.2 & 70 & 220 \\
\hline 4 & 0.4 & 5.5 & 33 & 400 \\
\hline 5 & 0.5 & 3.9 & 34 & 290 \\
\hline 6 & 0.7 & 3.5 & 35 & 230 \\
\hline 7 & 0.4 & 5.3 & 41 & 300 \\
\hline 8 & 0.4 & 4.1 & 39 & 230 \\
\hline Mean & 0.5 & 5.5 & 49 & 268 \\
\hline \multirow[t]{2}{*}{$\mathrm{SE}$} & 0.07 & 0.61 & 7.3 & 22.7 \\
\hline & NS & $P<0.05$ & NS & $P<0.02$ \\
\hline
\end{tabular}
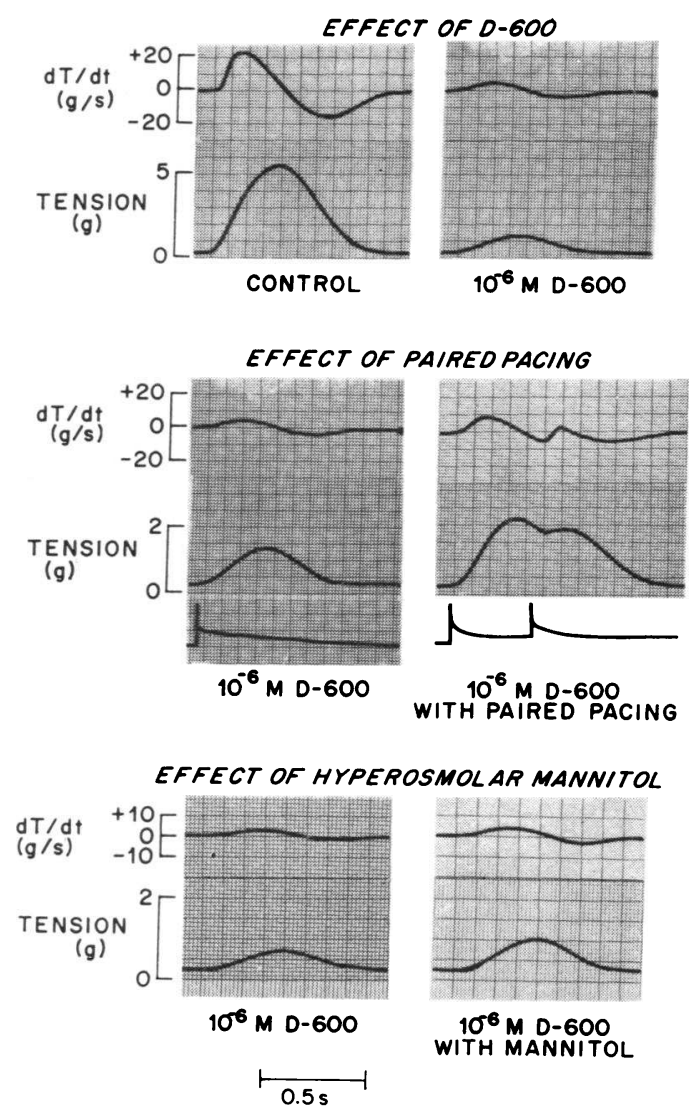

FIgURE 3 The top panel shows the depressant effect of a 1-h exposure to D600. The middle panel demonstrates that paired pacing still produces a significant increase in developed tension and $\mathrm{d} T / \mathrm{d} t$, even in the presence of D600. The bottom panel demonstrates that mannitol also continued to exert its inotropic effect even in the presence of D600, as evidenced by the increases in both tension and $\mathrm{d} T / \mathrm{d} t$ after mannitol.

inotropic effect produced by increasing extracellular calcium concentrations in the present study, as in others $(4,14)$, was observed to occur between 5.0 and $8.0 \mathrm{mM}$; there was no further increase as the extracellular calcium concentration was increased to 11.0 $\mathrm{mM}$. This suggests that intracellular calcium storage sites become functionally saturated with calcium as a consequence of the elevations of extracellular calcium, even though the total amount of bound calcium may continue to increase as extracellular concentrations rise still higher (18).

Like increased extracellular calcium concentration, paired electrical stimulation is thought to increase contractility by increasing the amount of calcium available at the myofilaments $(1,2,20)$. As has been reported previously under other experimental conditions (1), paired pacing provided no additional increase in the 
THE INFLUENCE OF D-600 ON TREPPE
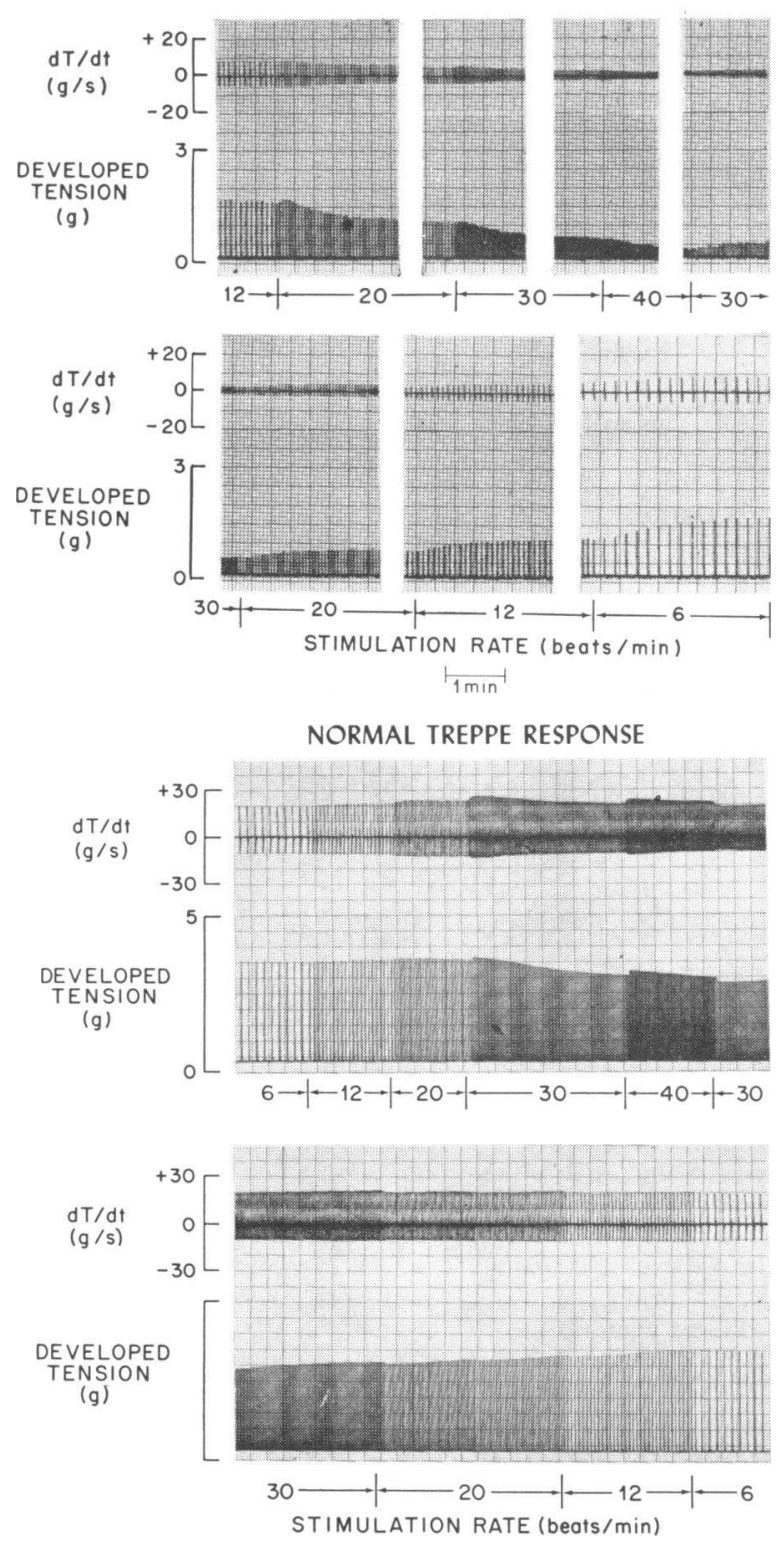

FIGURE 4 The effect of altered rates of stimulation in the presence (top panel) and absence (bottom panel) of D600 on isometrically contracting cat papillary muscles. The characteristic immediate increases in $\mathrm{d} T / \mathrm{d} t$ that accompany increased stimulation rate are prevented and reversed in the presence of D600. The effect of D600 on immediate changes in developed tension with increased stimulation rate is directionally similar but less marked. Note that the immediate increases in developed tension with increased stimulation rate are not sustained at the higher pacing rates even in the absence of D600.

rate of tension development in muscles exposed to maximal calcium in this study. The small increase in total tension development that occurred with paired pacing was a function of a prolongation in the time to peak tension rather than an increase in $\mathrm{d} T / \mathrm{d} t$. Thus, it appears that only the duration of the active state was changed, and not its intensity. It is the latter that is best correlated with the amount of calcium present at the myofilaments during contraction (21). These results suggest that the myofilament receptor complexes are functionally saturated when extracellular calcium levels exceed $8.0 \mathrm{mM}$, when a temperature of $37^{\circ} \mathrm{C}$ and pacing rate of $20 / \mathrm{min}$ are present.

On the other hand, $10^{-6} \mathrm{M}$ norepinephrine did produce a modest but significant increase in developed tension and in the maximal rate of tension rise over and above that resulting from maximal inotropic concentrations of extracellular calcium. This finding is not in agreement with some previous analyses of calcium-norepinephrine interaction (4). The reason for this discrepancy is not readily apparent, though it may be relevant to note that temperature, pacing rate, and glucose concentrations were all higher in our experiments. Whatever the reason, it appears from our results that under some conditions, norepinephrine retains the capacity to increase contractility in the face of maximal external calcium concentrations at a time when paired pacing is ineffective. At present it is not clear whether this reflects an ability of norepinephrine to increase some critical fraction of intracellular calcium above that possible by increasing extracellular concentrations of calcium or by paired pacing, or whether it implies that at least a portion of norepinephrine's inotropic potential is not calcium dependent. Additional investigations will be needed to settle this question.

The inotropic effect of hyperosmolality is critically influenced by extracellular calcium concentration. Like paired pacing, hyperosmolality failed to increase contractility when extracellular calcium was $10.0 \mathrm{mM}$. On the other hand, inhibition of intracellular systolic transfer of calcium with D600, a potent pharmacological inhibitor (5), failed to prevent the inotropic effect either of hyperosmotic mannitol or of paired pacing, though it did reduce and reverse the expected increase in $\mathrm{d} T / \mathrm{d} t$ resulting from increasing rate of stimulation (treppe effect) just as has been reported previously for verapamil, another inhibitor of intracellular transfer of calcium at the cell membrane (22).

Together, these observations suggest that the inotropic effect of hyperosmotic mannitol and of paired pacing, is dependent on changes in intracellular calcium but is not dependent on increases in the systolic transfer of calcium through the membrane channels that carry the slow inward current.

It remains possible, however, that calcium transfer across the cell membrane might be increased through channels that are not influenced by D600, or that hyper- 
osmolality might cause an increase in the amount of calcium released from intracellular storage sites during each action potential, as has been suggested to occur with paired stimulation. Also, augmentation of contraction by some mechanism that is not mediated by calcium remains a potential explanation for the persistent inotropic effect of mannitol after D600 blockade. Another and more obvious explanation is that, as KochWeser has implied, hyperosmolality may affect cardiac performance at least in part by passively increasing calcium availability to the myofilaments during contraction, as a consequence of cellular dehydration and a reduction in cell size (8). Cellular dehydration after exposure to severely hyperosmotic solutions (2-3X isotonicity) is manifested by gross swelling of the $T$ tubular system and a marked shrinkage in cell size (23). Others have shown that lesser degrees of hyperosmolality, such as were used in the present study, result in a loss of tissue water from beating heart tissues of approximately $10 \%$ (24). Koch-Weser (8) has shown that such a change occurs gradually over a period of $30 \mathrm{~min}$, by which time a new steady state has developed. This loss of tissue water would result passively in a corresponding increase in the concentration of cytoplasmic calcium for any given number of ions that are released into the cytoplasm (25). Nayler (26) has suggested a similar mechanism to explain the interaction of calcium and severe hypertonicity (two to three times normal) in determining the severity of contracture in toad myocardium.

The failure of hyperosmotic mannitol and sucrose to produce a significant increase in developed tension and $\mathrm{d} T / \mathrm{d} t$ in $10.0 \mathrm{mM}$ calcium is not simply a reflection of the muscles already contracting maximally, inasmuch as increases in performance were observed in response to norepinephrine in the same muscles under the same conditions. It might theoretically be possible that substrate limitation at the relatively high pacing rate $(20 / \mathrm{min})$ and temperature $\left(37^{\circ} \mathrm{C}\right)$ could inhibit responsiveness to hyperosmolality but not to a glycogenolytic agent such as norepinephrine. Such a possibility was considered in these studies, and additional experiments were performed in three papillary muscles at a pacing rate of $12 / \mathrm{min}$ and a temperature of $29^{\circ} \mathrm{C}$. These are conditions in which there would be much less chance that substrate availability might be a limiting factor. In each of these muscles developed tension and $\max \mathrm{d} T / \mathrm{d} t$ remained constant or declined after the addition of hypertonic mannitol to a solution containing $10.0 \mathrm{mM}$ calcium but rose after norepinephrine. In addition, the high glucose concentration (18 $\mathrm{mM}$ ) used in these experiments argues against the possibility that substrate limitation could be an explanation for the differences in the response to hyperosmotic agents and norepinephrine.

We were also concerned by the possibility that the observed unresponsiveness to hyperosmolality at extracellular calcium concentration of $10.0 \mathrm{mM}$ might have been a consequence of general deterioration of the preparation with time. Accordingly, two additional experiments were made in which fresh muscles were placed into $10.0 \mathrm{mM}$ calcium after a brief equilibration period in $2.5 \mathrm{mM}$ calcium and subsequently exposed to mannitol after a very short period in vitro. Results in these muscles were identical to those described earlier: mannitol had no inotropic effect.

In summary, the present study provides further evidence that hyperosmolality, paired electrical stimulation, and norepinephrine exert a potent inotropic influence on isolated cardiac muscle at normal calcium concentrations. In addition, the results show that the effectiveness of hyperosmolality, like that of paired electrical stimulation, is critically influenced by extracellular calcium concentration, but that the inotropic effect of norepinephrine, while reduced, is not prevented by maximal functional extracellular calcium concentrations. Moreover, inhibition of systolic calcium flux by a potent pharmacological inhibitor, D600, does not prevent the inotropic response to hypertonic mannitol. Finally, it is of special interest that D600 was found to reduce and in fact reverse the expected increase in $\mathrm{d} T / \mathrm{d} t$ with treppe but not that of paired electrical stimulation. Thus, the drug's inhibition of the cell's ability to transport calcium through channels that carry the slow inward current during systole $(5,22)$ seems to disclose a fundamental difference in the mechanism of action of the two interventions. Further definition of this difference should provide a fruitful area for future study.

\section{ACKNOWLEDGMENTS}

The authors are grateful to Dr. A. Fleckenstein for supplying D600 and to Dr. A. Schwartz for helpful advice. The authors wish to express their appreciation to Pat Wells for secretarial assistance.

The work was supported in part by the Moss Heart Fund, a contract from the National Heart and Lung Institute (NHLI) (NHLI-72-2947), grants from the NHLI (HL 15522 and HL 06296), and a grant from The American Heart Association, Inc.

\section{REFERENCES}

1. Nayler, W. G. 1961. The importance of calcium in poststimulation potentiation. J. Gen. Physiol. 44 : 10591072.

2. Koch-Weser, J., and J. R. Blinks. 1963. The influence of the interval between beats on myocardial contractility. Pharmacol. Rev. 15 : 601-652. 
3. Friedman, W. F., R. A. Buccino, E. H. Sonnenblick, and E. Braunwald. 1967. Effects of frequency of contraction and ionic environment on the responses of heart muscle to acetylcholine. Circ. Res. 21: 573-582.

4. Sonnenblick, E. H., W. W. Parmley, R. A. Buccino, and J. F. Spann, Jr. 1968. Maximum force development in cardiac muscle. Nature (Lond.). 219: 1056-1058.

5. Fleckenstein, A. 1971. Specific inhibitors and promoters of calcium action in the excitation-contraction coupling of heart muscle and their role in the prevention or production of myocardial lesions. In Calcium and the Heart. P. Harris and L. H. Opie, editors. Academic Press, Inc., New York. 135-188.

6. Wildenthal, K., D. S. Mierzwiak, and J. H. Mitchell. 1969. Acute effects of increased serum osmolality on left ventricular performance. Am. J. Physiol. 216: 898904.

7. Atkins, J. M., K. Wildenthal, and L. D. Horwitz. 1973. Cardiovascular responses to hyperosmotic mannitol in anesthetized and conscious dogs. Am. J. Physiol. 225: 132-137.

8. Koch-Weser, J. 1963. Influence of osmolarity of perfusate on contractility of mammalian myocardium. Am. J. Physiol. 204: 957-962.

9. Wildenthal, K., C. L. Skelton, and H. N. Coleman, III. 1969. Cardiac muscle mechanics in hyperosmotic solutions. Am. J. Physiol. 217 : 302-306.

10. Willerson, J. T., W. J. Powell, Jr., T. E. Guiney, J. J. Stark, C. A. Sanders, and A Leaf. 1972. Improvement in myocardial function and coronary blood flow in ischemic myocardium after mannitol. J. Clin. Invest. 51: 2989-2998.

11. Willerson, J. T., M. L. Weisfeldt, C. A. Sanders, and W. J. Powell, Jr. 1974. Influence of hyperosmolar agents on hypoxic cat papillary muscle function. Cardiovasc. Res. 8: 8-17.

12. Templeton, G. H., J. H. Mitchell, and K. Wildenthal. 1972. The influence of hyperosmolality on left ventricular stiffness. Am. J. Physiol. 222: 1406-1411.

13. Little, G. R., and W. W. Sleator. 1969. Calcium exchange and contraction strength of guinea pig atrium in normal and hypertonic media. J. Gon. Physiol. 54: 494-511.

14. Langer, G. A. 1971. The intrinsic control of myocardiol contraction-ionic factors. N. Engl. J. Med. 285: 10651071
15. Feigl, E. O. 1967. Effects of stimulation frequency on myocardial extensibility. Circ. Res. 20: 447-458.

16. Sonnenblick, E. H., J. Ross, Jr., J. W. Covell, and E. Braunwald. 1966. Alterations in resting length-tension relations of cardiac muscle induced by changes in contractile force. Circ. Res. 19: 980-988.

17. Winegrad, S., and A. M. Shanes. 1962. Calcium flux and contractility in guinea pig atria. J. Gen. Physiol. 45: 371-394.

18. Ueba, Y., Y. Ito, and C. A. Chidsey, III. 1971. Intracellular calcium and myocardial contractility. I. Influence of extracellular calcium. Am. J. Physiol. 220: 1553-1557.

19. Ebashi, S., and M. Endo. 1968. Calcium ion and muscle contraction. Prog. Biophys. Mol. Biol. 18: 123-183.

20. Suko, J., Y. Ueba, and C. A. Chidsey. 1970. Intracellular calcium and myocardial contractility. II. Effects of postextrasystolic potentiation in the isolated heart. Circ. Res. 27 : 227-234.

21. Buccino, R. A., E. H. Sonnenblick, J. F. Spann, Jr., W. F. Friedman, and E. Braunwald. 1967. Interactions between changes in the intensity and duration of the active state in the characterization of inotropic stimuli on heart muscle. Circ. Res. 21: 857-867.

22. Lindenmayer, G. E., J. L. McCans, R. G. Munson, D. C. Koreger, and A. Schwartz. 1973. Evidence that increased frequency (Bowditch-"Bow") and glycoside (Gly) inotropic interventions are mediated by separate mechanisms: use of verapamil®. Fed. Proc. 32: 685. (Abstr.)

23. Sperelakis, N., and R. Rubio. 1971. Ultrastructural changes produced by hypertonicity in cat cardiac muscle. J. Mol. Cell. Cardiol. 3: 139-156.

24. Brachfeld, N., J. Christodoulou, N. Keller, T. Killip, and C. Smithen. 1973. Hemodynamic, metabolic and ultrastructural consequences of hyperosmolal mannitol following myocardial anoxia. Symposium of the 6th Annual Meeting of the International Study Group for Research in Cardiac Metabolism, Freiburg, Germany.

25. Bozler, E. 1961. Electrolytes and osmotic balance of muscle in solutions of nonelectrolytes. Am. J. Physiol. 200: 656-657.

26. Nayler, W. G. 1961. Influence of hypertonic solutions on ventricular contractile activity. Am. J. Physiol. 201 : $682-686$. 